\title{
Hydrodynamics of a three-phase external-loop airlift bioreactor
}

\author{
Carla Freitas ${ }^{\mathrm{a}}$, Maria Fialová ${ }^{\mathrm{b}}$, Jindrich Zahradnik ${ }^{\mathrm{b}}$, José A. Teixeira ${ }^{\mathrm{a}, *}$ \\ ${ }^{a}$ Centro de Engenharia Biológica - IBQF, Universidade do Minho, Campus de Crvaltar, 4710-057 Braga, Portugal \\ ${ }^{\mathrm{b}}$ Institute of Chemical Process Fundamentals, Academy of Sciences of the Czech Republic, 16502 Prague 6 - Suchdol, Czech Republic
}

Received 28 September 1999; accepted 20 March 2000

\begin{abstract}
The effect of the distributing plate orifice diameter, airflow rate, solids loading and solids density on the hydrodynamic characteristics - gas holdup, circulation time and liquid velocity - of a three-phase external-loop airlift reactor was characterized. It was observed that the gas distributor has a small effect on riser gas holdup, circulation time and downcomer liquid velocity. On the contrary, the airflow rate, solids loading and solids density significantly affect the hydrodynamic characteristics of the external-loop airlift reactor. A previously described model was used to estimate simultaneously both the riser gas holdup and the downcomer linear liquid velocity. The model simulated with high-accuracy experimental data obtained with three different distributing plate orifice diameters, two solids density and solids loading up to 30\% (v/v). (C) 2000 Elsevier Science Ltd. All rights reserved.
\end{abstract}

Keywords: Multiphase reactor; Hydrodynamics; Mathematical model; Distributing plate; Solid phase

\section{Introduction}

With their increasing applications to biotechnology processes, airlift reactors appear to be one of the most important bioreactor configurations. Airlift reactors are reaction vessels divided into two sections - the riser, where the gas is injected, and the downcomer - and are classified according to the way in which the loop for circulating the liquid is arranged. The internal-loop airlift reactors contain the riser and the downcomer in the same column and in the external-loop reactors the downcomer and the riser are separate tubes put up side by side and connected at the top and at the bottom. Characteristic properties of external-loop airlift reactors are (Onken \& Weiland, 1983): (a) a complete degassing of the liquid at the top, which prevents accumulation of $\mathrm{CO}_{2}$ in the fermentation of liquid and the reduction of the driving force for oxygen transfer due to entrainment of bubbles lean in oxygen; (b) no zones of irregular flow at top and bottom of the fermenter; (c) easy removal of heat from the fermenter; and (d) easy measurement and control of liquid circulation rate in the downcomer without complications arising from the gas content.

\footnotetext{
* Corresponding author. Tel.: + 351-253-604400; fax: + 351-253678986.

E-mail address: jateixeira@deb.uminho.pt (J-. A. Teixeira).
}

External-loop fermenters have frequently been used in investigations of reactor behaviour in laboratory, bench-scale and pilot-plant installations, apparently because of the well-defined conditions in the system. However, the amount of generalized information available is small. This is due to the fact that, for a given superficial gas velocity value, any variation of gas or liquid physical properties, downcomer and riser cross-section ratio, top and bottom riser and downcomer connecting sections geometry, phase separation conditions, liquid volume, reactor height or gas distributing plate, generates a modification in liquid velocity and gas-holdup (Bentifraouine, Xuereb \& Riba, 1997). The complexity increases when a third phase (solid) is added to the system. The majority of data have been obtained for air-water systems that are not necessarily representing the fermentation processes, which are characterized by the presence of a solid phase slightly denser than water and where high concentrations of solids may occur. Kochbeck, Lindert and Hampel (1992) observed that liquid velocity in an external-loop airlift reactor was drastically reduced by the presence of high-density solid particles. Working with low-density solids and with high amounts of solids (till $30 \% \mathrm{v} / \mathrm{v}$ ), Freitas and Teixeira (1997) found that solids loading and density had a considerable influence on gas holdup, liquid velocity and mixing time of an internal-loop airlift reactor with a degassing zone. 
Parameters of the gas distributing system, in particular free plate area and orifice diameter, have been shown to influence strongly the gas holdup values in bubble columns (Kastánek, Zahradnik, Kratochvil and Cermak, 1993), once the bubble size is affected. Gas holdup in an airlift reactor is a parameter of great importance, not only for its effect on the circulation rate of the liquid but also for its consequence on gas residence time, oxygen transfer and liquid mixing. However, relatively little attention has been paid to the effect of gas distribution in airlift reactors and there are no data published about its influence on the performance of three-phase reactors. For gas-liquid systems, Merchuk (1986) reported, for an external-loop airlift reactor, that there was no difference in the gas holdup and liquid velocity for different holes diameters of the distributing plate. Also for a two-phase system and an external-loop airlift reactor, different results were obtained by Snape, Fialova, Zahradnik and Thomas (1992) when investigating the effect of the distributing plate geometry on gas holdup and liquid velocity. They found that the plate with $0.5 \mathrm{~mm}$ orifices had a markedly different behaviour than the plates with higher orifices diameters while only slight increase of gas holdup and liquid velocity with decreasing orifice diameter was observed in the range of orifice diameter $1.0-3.0 \mathrm{~mm}$.

Models for the prediction of the hydrodynamics of airlift reactors have been described in the literature (Chisti, Halard, and Moo-Young, 1988; Garcia-Calvo \& Letón, 1996; Gavrilescu \& Tudose, 1998; Hwang \& Cheng, 1997; Kemblowski, Przywarski \& Diab, 1993). Such models are based, usually, on momentum or energy balances, taking into account the energy losses along the total circulation loop. The difficulties in evaluating the energy loss along the total circulation loop in the airlift reactor stem partly from the complex nature of the flowing mixture and partly from the difference in the factors controlling the energy loss process (Gavrilescu $\&$ Tudose, 1998). Even more difficulties arise from the introduction of a solid phase, since the influence of the solids - which may change quantity, density and/or size - on the energy loss and, hence, on hydrodynamics is of very difficult prediction. Thus, only few of the models in the literature describe the hydrodynamics of three-phase airlift reactors being developed for only one type or amount of solids. In a previous work (Freitas et al., 1999), a model for the estimation of gas holdup and liquid velocity in three-phase airlift reactors was developed and validated for both an external- and an internal-loop airlift reactor. The riser gas holdup estimation is done using a modification of Zuber and Findlay model:

$$
\varepsilon_{g r}=\frac{U_{g r}}{C\left[U_{g r}+U_{l r}\left(1+\varepsilon_{s r} /\left(1-\varepsilon_{g r}-\varepsilon_{s r}\right)\right)-\varepsilon_{s r} U_{s t}\right]+U_{b t}},
$$

where $C$ is the distributing factor and $U_{b t}$ the terminal rise velocity of a single bubble.

An energy balance was used for the prediction of the riser superficial liquid velocity:

$$
\begin{aligned}
2_{g} H \varepsilon_{g r}= & {\left[\frac{\left(H_{r}+H_{t}\right) D_{r}^{-1.25}}{\left(1-\varepsilon_{g r}-\varepsilon_{s}\right)^{1.75}}+\left(\frac{A_{r}}{A_{d}}\right)^{1.75}\right.} \\
& \left.\times \frac{\left(H_{d}+H_{b}\right) D_{d}^{-1.25}}{\left(1-\varepsilon_{s}\right)^{1.75}}\right] \beta U_{l r}^{1.75}+k_{f r, t} \frac{U_{l r}^{2}}{\left(1-\varepsilon_{g r}-\varepsilon_{s}\right)^{2}} \\
& +\left[\left(\frac{A_{r}}{A_{t, d}}\right)^{2}\left(k_{f t, d}+k_{f g c}\right)\right. \\
& \left.+\left(\frac{A_{r}}{A_{d}}\right)^{2}\left(k_{f s c}+k_{f d, b}+k_{f b, r}\right)\right] \frac{U_{l r}^{2}}{\left(1-\varepsilon_{s}\right)^{2}}
\end{aligned}
$$

the parameter $\beta$ being given by

$\beta=\alpha 40.0791 \mu_{h}^{0.25} \rho_{h}^{-0.25}$.

Downcomer linear liquid velocity is given by

$v_{l d}=\frac{A_{r}}{A_{d}} \frac{U_{l r}}{\left(1-\varepsilon_{s}\right)}$.

Values of riser gas holdup and downcomer linear liquid velocity are obtained using an optimization procedure, with the calculation of the optimum values of the parameters $C, U_{b t}$ and $\beta$.

In order to obtain further information about the behaviour of three-phase external-loop reactors working with low-density particles, the effect of airflow rate, solids loading, solids density and orifice diameter of the distributing plate on riser gas holdup, downcomer liquid velocity circulation time and were systematically studied. The model developed by Freitas et al. (1999) was used to estimate values of riser gas holdup and downcomer linear liquid velocity on the three-phase external-loop airlift reactor working with different distributing plate orifice diameters, two solids densities and solids loading up to $30 \%(\mathrm{v} / \mathrm{v})$.

\section{Experimental}

Experiments were performed in a glass wall externalloop airlift reactor with a working volume of 601 (schematically depicted in Fig. 1). The downcomer and riser diameters are 0.05 and $0.158 \mathrm{~m}$, respectively, with $2.07 \mathrm{~m}$ of height. The height and the diameter of top section are 0.36 and $0.158 \mathrm{~m}$, respectively, with a contraction that connects to a bend with $0.107 \mathrm{~m}$ diameter. The bottom section has the same diameter as the downcomer. The downcomer flow joins the riser $0.05 \mathrm{~m}$ above the distributing plate.

Air was used as gas phase and injected through perforated plates with a constant free plate area ratio $\phi=0.2 \%$ 


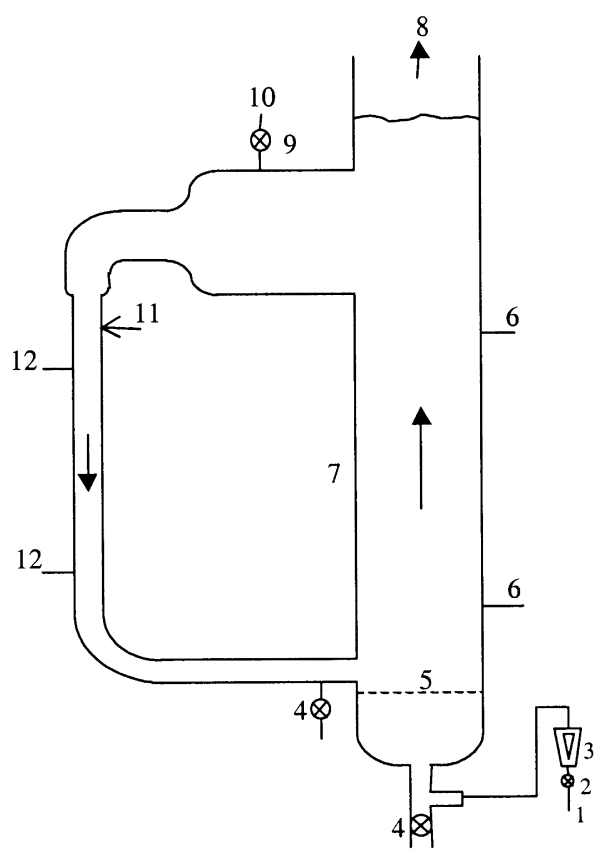

Fig. 1. Schematic representation of the experimental airlift reactor: 1 - air feed; 2 - regulation valve; 3 - rotameter; 4 - exit valve; 5 - sieve plate; 6 - pressure taps; 7 - reactor vessel; 8 - air vent; 9 - valve; 10 - water feed; 11 - tracer injection; 12 - measuring electrodes.

and hole diameters of $0.5,1.0$ and $1.6 \mathrm{~mm}$. The airflow rate was varied between 2100 and $11800 \mathrm{l} / \mathrm{h}$ corresponding to riser superficial gas velocities, based on the riser cross-section area, between 0.03 and $0.17 \mathrm{~m} / \mathrm{s}$, respectively.

Water was used as liquid phase and Ca-alginate beads, with two different densities, were used as solid phase and prepared according to the procedure described by Vicente and Teixiera (1995). The mean diameter and density of the "low-density solids" (LD) were $(2.131 \pm 0.102) \mathrm{mm}$ and $(1023 \pm 1) \mathrm{kg} / \mathrm{m}^{3}$, respectively, and the values for the "high-density solids" (HD) were $(2.151 \pm 0.125) \mathrm{mm}$ and $(1048 \pm 1) \mathrm{kg} / \mathrm{m}^{3}$. For each type of solids, solids loading applied was $0,5,10,15,20$ and $30 \%(\mathrm{v} / \mathrm{v})$.

The average volumetric riser gas holdup $\left(\varepsilon_{g r}\right)$ was calculated from the manometric measurements of hydrostatic pressure in the riser.

Two identical conductometers equipped with conductivity probes, separated by $1.56 \mathrm{~m}$, were used to characterize the liquid-phase flow in the downcomer. For each set of experimental conditions, a pulse of saturated potassium chloride solution $(\mathrm{KCl})$ was injected, at time zero, into the downcomer, $0.285 \mathrm{~m}$ above the top conductivity probe. The amount of $\mathrm{KCl}$ added was small enough not to affect the coalescence behaviour of the gasliquid system (Zahradnik, Fialova, Kastanek, Green \& Thomas, 1995). The data-acquisition was stopped once a constant conductivity value was achieved. The responses of the two probes were transmitted to a computer by a data-acquisition system. Three replicates were made for each set of experimental conditions.

The downcomer linear liquid velocity $\left(v_{l d}\right)$ was calculated dividing the distance between the two probes by the time $(\Delta t)$ required by the tracer to travel from one to the other.

The circulation time $\left(t_{c}\right)$ was computed by averaging the time spans between maximum consecutive peaks in the conductivity probe response curve and it was obtained independently for each of the two conductivity probes. The final value, for each set of experimental conditions, is the average between the values registered by the two probes in the three replicates made.

The optimization of the parameters $C, U_{b t}$ and $\beta$ (Eqs. (1)-(4)), allowing for the prediction of values of riser gas holdup and the downcomer linear liquid velocity, was done using a developed computer software.

\section{Results and discussion}

\subsection{Gas holdup}

Gas holdup is one of the most important parameters characterizing bubble bed hydrodynamics. Its value determines the fraction of gas in the bubble bed and thus, the residence time of phases in the bed, for given values of gas flow rates (Kastánek et al., 1993). Moreover, the difference between gas holdup in the riser and in the downcomer is responsible for the circulation in the reactor. In this work, gas holdup was measured in the riser, for different experimental conditions. Fig. 2, in which values of riser gas holdup $\left(\varepsilon_{g r}\right)$ are plotted, for the two solids density studied, as a function of riser superficial gas velocity $\left(u_{g r}\right)$ and solids loading, represents the effect of the distributing plate orifice diameter on $\varepsilon_{g r}$. It can be seen that, in all situations, riser gas holdup increases with riser superficial gas velocity. For water $(0 \%$ of solids), the distributing plate of $0.5 \mathrm{~mm}$ orifices shows a different behaviour when compared with the other two plates (similar to the results obtained by Snape et al., 1992). Gas holdup increases rapidly with gas superficial gas velocity, appears to be reaching a stationary value and then increases again. These changes of slope in the relation between riser gas holdup and riser superficial gas velocity and the existence of an almost plateau-like transition region between 0.03 and $0.113 \mathrm{~m} / \mathrm{s}$ can be ascribed to the change of bubbling mode in the riser, analogous to the transition between homogeneous and heterogeneous bubbling regimes commonly reported for bubble column reactors (Kastánek et al., 1993). However, the transition is smoother in the airlift reactor than in the bubble column (as reported by Snape, Zahradnik, Fialova \& Thomas, 1995), probably because the superimposed 
(a)
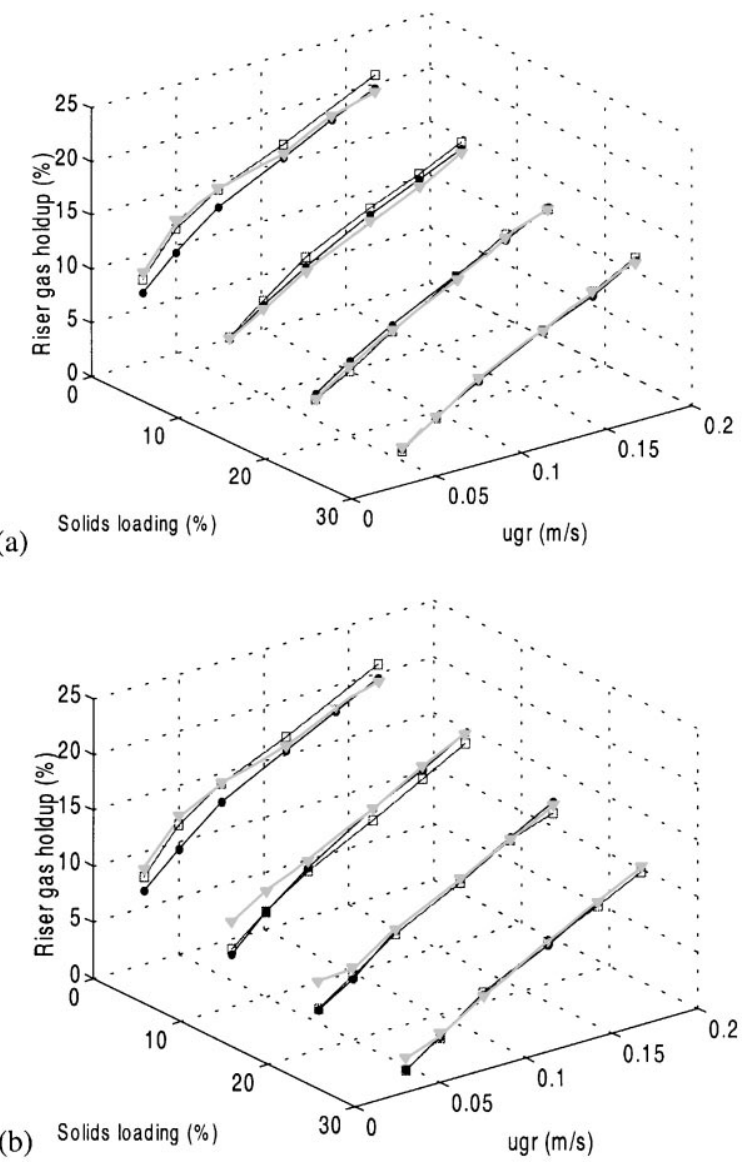

Fig. 2. Influence of solids loading and riser superficial gas velocity $\left(u_{g r}\right)$ on the riser gas holdup, for three distributing plate orifice diameters ( $-1.6 \mathrm{~mm} ; \square-1.0 \mathrm{~mm} ; \boldsymbol{\nabla}-0.5 \mathrm{~mm}$ ): (a) "low-density solids"; (b) "high-density solids".

liquid circulation reduces, but does not completely suppresses, the influence of plate geometry on bubbling regime. The transition is less pronounced for $1.0 \mathrm{~mm}$ holes and does not exist for $1.6 \mathrm{~mm}$ holes or three-phase systems, for which the increase of riser gas holdup with the increase of riser superficial gas velocity is typical from a heterogeneous flow.

It can also be seen in Fig. 2 that the influence of the orifice diameters of the distributing plates on riser gas holdup is not very significant. In accordance with this, Chisti (1989) reported that, for properly designed perforated plates, factors as the number of holes and the free plate area have been found to have little effect on gas holdup in tall airlift reactors operated with several different fluids. In this work, for the two-phase system $(0 \%$ of solids) and the lower solids loading, the increase of orifice diameter leads to a decrease in riser gas holdup but its influence is negligible for solids loading higher than $10 \%$. The orifice diameter of the distributing plate influences the size of the bubbles as they leave the plate, the larger the orifice the larger the initial bubble size. Residence

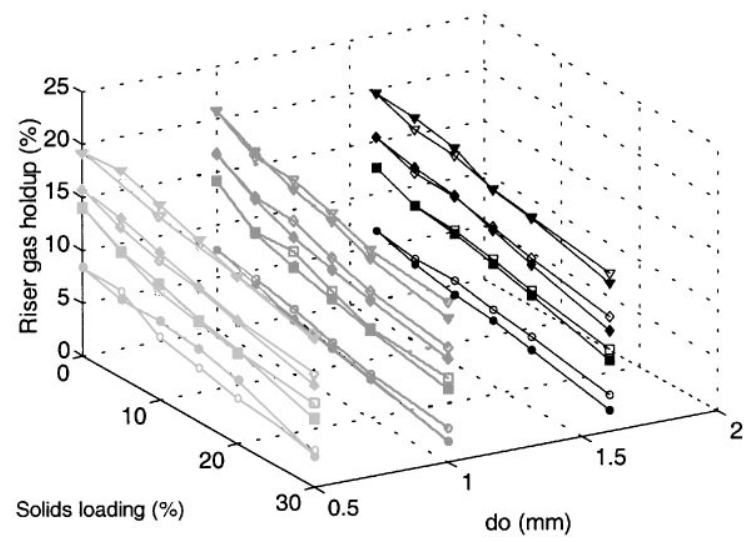

Fig. 3. Influence of solids loading and solids density on riser gas holdup, for three distributing plate orifice diameters $\left(d_{o}\right)$ and for different airflow rates $(2100 \mathrm{l} / \mathrm{h}: \bigcirc-\mathrm{LD}, \bigcirc-\mathrm{HD} ; 5300 \mathrm{l} / \mathrm{h}: \square-\mathrm{LD}, \mathbf{\square}-\mathrm{HD}$; $8000 \mathrm{l} / \mathrm{h}: \diamond-\mathrm{LD}, \diamond-\mathrm{HD} ; 11800 \mathrm{l} / \mathrm{h}: \nabla$ - LD, $\boldsymbol{\nabla}$ - HD): LD - "low-density solids"; HD - "high-density solids".

time of the bigger bubbles is lower than that of the smaller ones, once they have higher rise velocities, resulting in lower gas holdup. However, under the highly turbulent conditions typically found in bioreactors, the bubble size in dispersion is generally independent of the size at birth and it is controlled by the equilibrium between the dynamic pressure forces - which works to break the bubble - and the surface tension force - which attempts to preserve its size and shape (Chisti, 1989). For high amounts of solids, bubbles can no longer be considered to act independently and bubble coalescence and breakup become important factors - the differences between initial bubble size generated by the three types of the distributing plates are suppressed. Moreover, the suppression of gas distributor effect is enhanced by the influence of the superimposed liquid flow on the flow pattern and on bubble rising velocity in the riser (Snape et al., 1995). This is the reason why the differences between distributing plates decrease for high values of riser superficial gas velocity.

Fig. 3 shows the influence of solids loading and solids density on riser gas holdup, for the three distributing plates used. The effect of solids loading is clear, once the progressive introduction of solids in the system results in a significant decrease of riser gas holdup. This is due to increasing reduction of flow area of the gas and liquid phases and the consequent increase of coalescence. Similar results were obtained by Lu, Hwang and Chang (1995), Verlaan and Tramper (1987) and Freitas and Teixeira (1997).

Also from Fig. 3, it seems that, in general, solids density has little influence on riser gas holdup, independent of the distributing plate used, being observed only in some cases small decreases of riser gas holdup with the increase of solids density. 


\subsection{Circulation time}

In Fig. 4, circulation time $\left(t_{c}\right)$ is plotted, for both solids density and the three distributing plates used, as a function of riser superficial gas velocity $\left(u_{g r}\right)$ and solids loading. For low airflow rates, circulation time is a strong function of the riser superficial gas velocity, decreasing with the increase of the airflow rate. For higher airflow rates, circulation time dependence on airflow rate becomes very small.

In agreement with the results obtained for riser gas holdup (Fig. 2), the circulation time is only significantly affected by the distributing plate orifice diameter for low values of solids loading. For $0 \%$ of solids, circulation time increases with the orifice diameter and, for $10 \%$ of "high-density solids", circulation time is also lower for the $0.5 \mathrm{~mm}$ distributing plate. For higher amounts of solids, the circulation time does not have a defined trend, as expected, since the riser gas holdup is also influenced only by the distributing plate for low solids loading. In these cases, as riser gas holdup decreases with the increase of the orifice diameter of the distributing plate, the
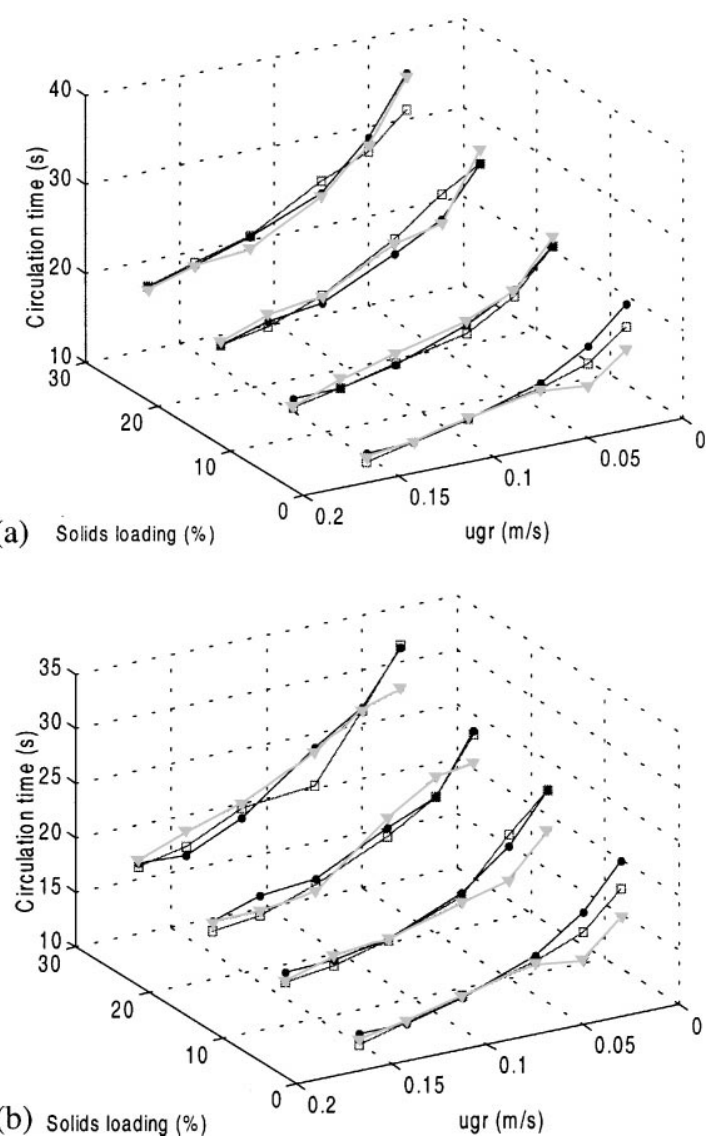

Fig. 4. Influence of solids loading and riser superficial gas velocity $\left(u_{g r}\right)$ on circulation time, for three distributing plate orifice diameters ( $-1.6 \mathrm{~mm} ; \square-1.0 \mathrm{~mm} ; \boldsymbol{\nabla}-0.5 \mathrm{~mm}$ ): (a) "low-density solids"; (b) "high-density solids".

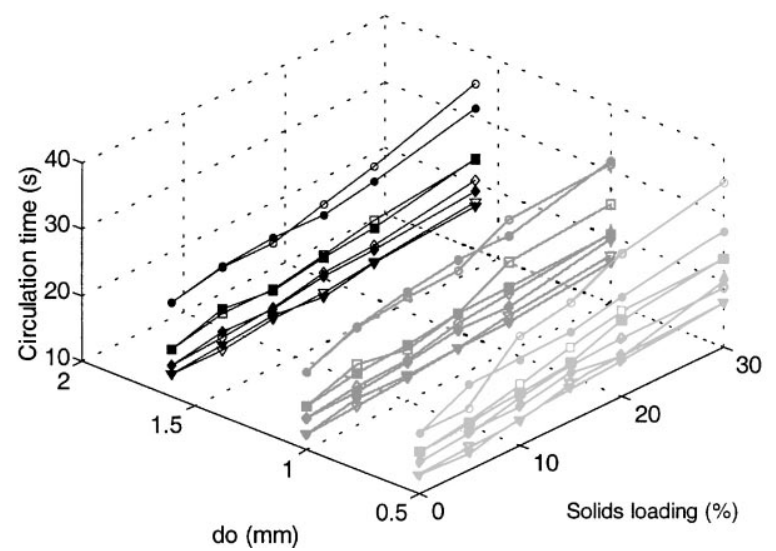

Fig. 5. Influence of solids loading and solids density on circulation time, for three distributing plate orifice diameters $\left(d_{o}\right)$ and for different airflow rates $(2100 \mathrm{l} / \mathrm{h}: \bigcirc-\mathrm{LD}, \bigcirc-\mathrm{HD} ; 5300 \mathrm{l} / \mathrm{h}: \square-\mathrm{LD}, \mathbf{\square}-\mathrm{HD}$; 8000 l/h: $\diamond-$ LD, $\diamond$ HD; 11800 l/h: $\nabla$ - LD, $\nabla$ - HD): LD - "low-density solids"; HD - "high-density solids".

driving force for liquid circulation becomes smaller and, hence, the circulation time becomes larger. For high solids loading, probably because of the different amounts of bubbles entered into the downcomer for the three distributing plates, the difference between riser and downcomer gas holdup is affected in different ways, which could explain the uncertainty of the influence of the distributing plates on the circulation time in these cases. However, the differences observed are very small which leads us to conclude that the distributing plate orifice diameter has a small influence on circulation time for high solids loading.

The influence of solids loading and density on the circulation time is represented in Fig. 5. The increase of solids loading produces an increase of the circulation time, due to the decrease of driving force for circulation, as the riser gas holdup is also reduced by the introduction of solids (Fig. 3).

It can also be seen in Fig. 5 that the increase in solids density leads to a decrease of the circulation time, especially for low airflow rates, while for high values of airflow rate the effect of the density is negligible. The influence of solids density on circulation time is also reduced by the increase of the orifice diameter of the distributing plate. Still, even in small amounts, circulation time decreases with solids density for both 1.0 and $1.6 \mathrm{~mm}$. Despite the fact that downcomer gas holdup in external-loop airlift reactors is usually very small, with air bubbles coalescence occurring in the riser and with the corresponding increase of the rising bubble velocity, few bubbles enter the downcomer. Thus, the difference between riser and downcomer gas holdup seems to increase with the increase of solids density, resulting in a lowering of the circulation time. 


\subsection{Liquid velocity}

Figs. 6 and 7 present the influence of the distributing plate orifice diameter on downcomer linear liquid velocity, for the "low-" and "high-density solids", respectively. With each experimental data the standard deviation associated is shown. As can be seen, there is no evident effect of the studied characteristics of the distributing plate on the liquid velocity. It can only be said for certain that, for $10 \%$ of solids, downcomer linear liquid velocity is lower for the $0.5 \mathrm{~mm}$ plate.

In all the cases studied, downcomer liquid velocity responds in a similar way to the aeration rate, increasing with the increase of riser superficial gas velocity, which is an expected result. At small gas throughputs, the gas holdup in the riser increases considerably more with increasing gas velocity than in the downcomer. Thus, the resulting large driving force leads to a large increase of liquid velocity for low superficial gas velocities, whereas at larger gas throughputs the liquid velocity tends to level off (Weiland, 1984).

Also from Figs. 6 and 7, it can be seen that the dependences of downcomer linear liquid velocity on riser superficial gas velocity become, generally, flatter with increasing solids loading.
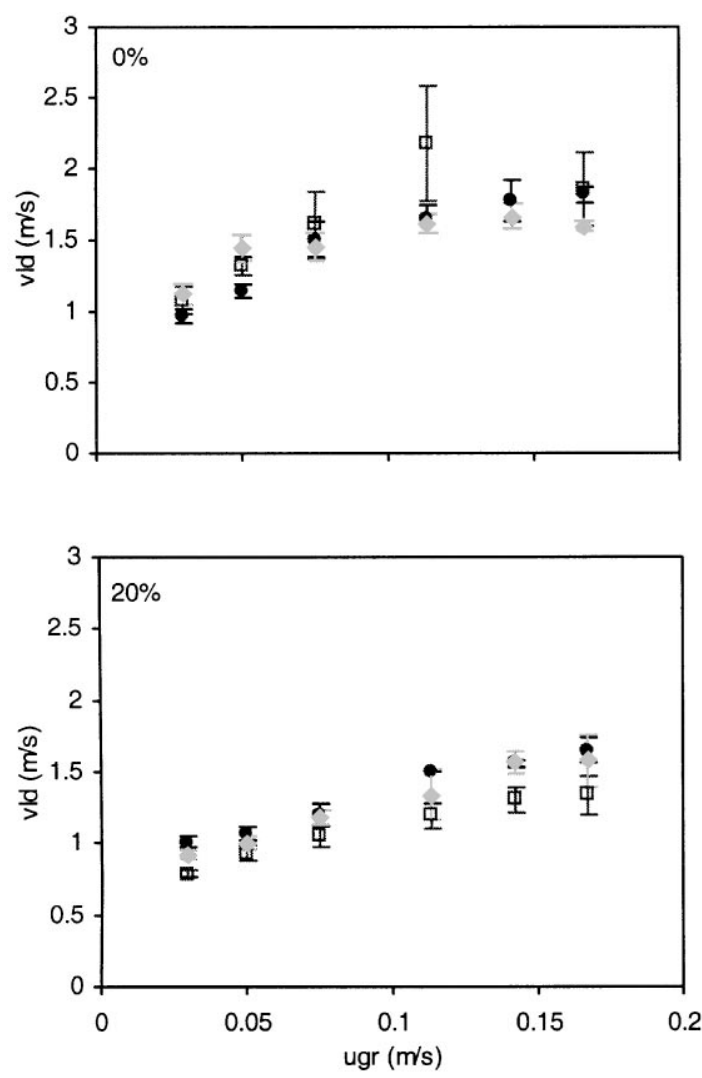

The influence of solids loading on downcomer linear liquid velocity is shown in Fig. 8. Downcomer liquid velocity decreases with solids loading as a consequence of the increase of bubble coalescence (reflected on the decrease of riser gas holdup shown in Fig. 2) and of the frictional loss caused by the reduction of the flow area of the gas and liquid phases. Similar results were reported by Lu et al. (1995).

Fig. 8 also compares the downcomer linear liquid velocity for "high-" and "low-density solids" allowing for the conclusion that, generally, solids density produces an increase of the downcomer liquid velocity. This is in accordance with what was presented in Fig. 5, where circulation time decreases with solids density, once for this to happen downcomer liquid velocity has to increase. Also as for the circulation time, solids density has a lower influence on downcomer liquid velocity for the higher distributing plate orifice diameter.

\subsection{Application of the hydrodynamic model}

In Figs. 9 and in 10 are shown the results of the simulations done for the estimation of riser gas holdup and downcomer linear liquid velocity, respectively, for three distributing plates, two solids density and solid
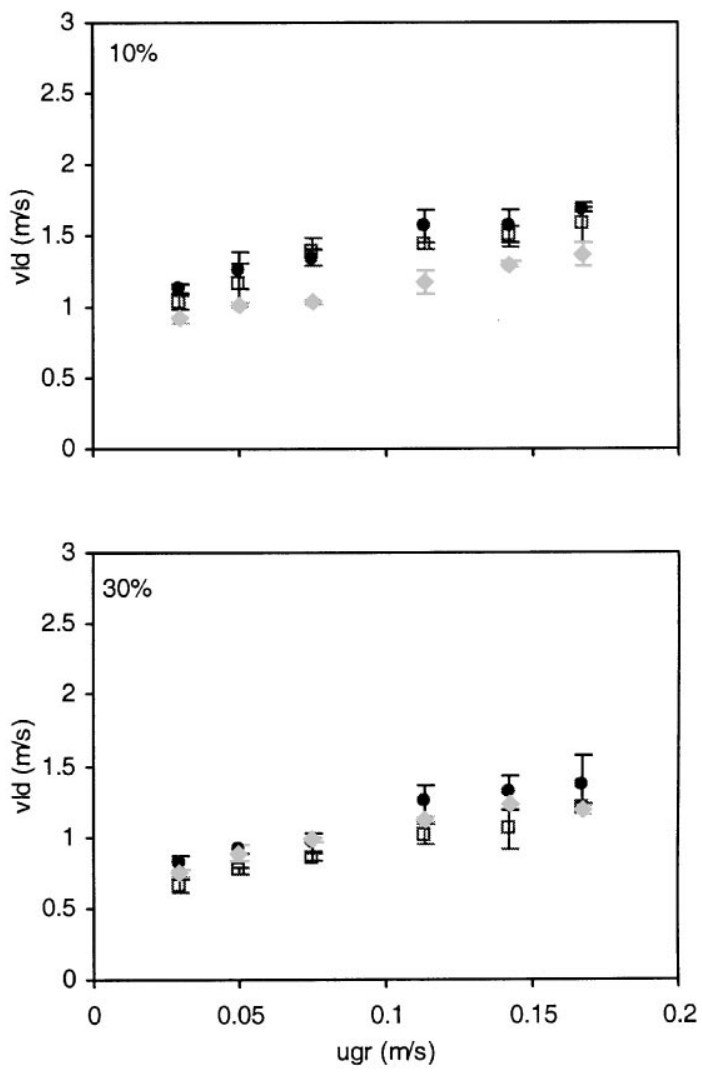

Fig. 6. Influence of riser superficial gas velocity $\left(u_{g r}\right)$ on the downcomer linear liquid velocity $\left(v_{l d}\right)$, for different solids loading $(0,10,20$ and $30 \% \mathrm{v} / \mathrm{v})$ and three distributing plate orifice diameters $(-1.6 \mathrm{~mm} ; \square-1.0 \mathrm{~mm} ;-0.5 \mathrm{~mm})$ - "low-density solids". 

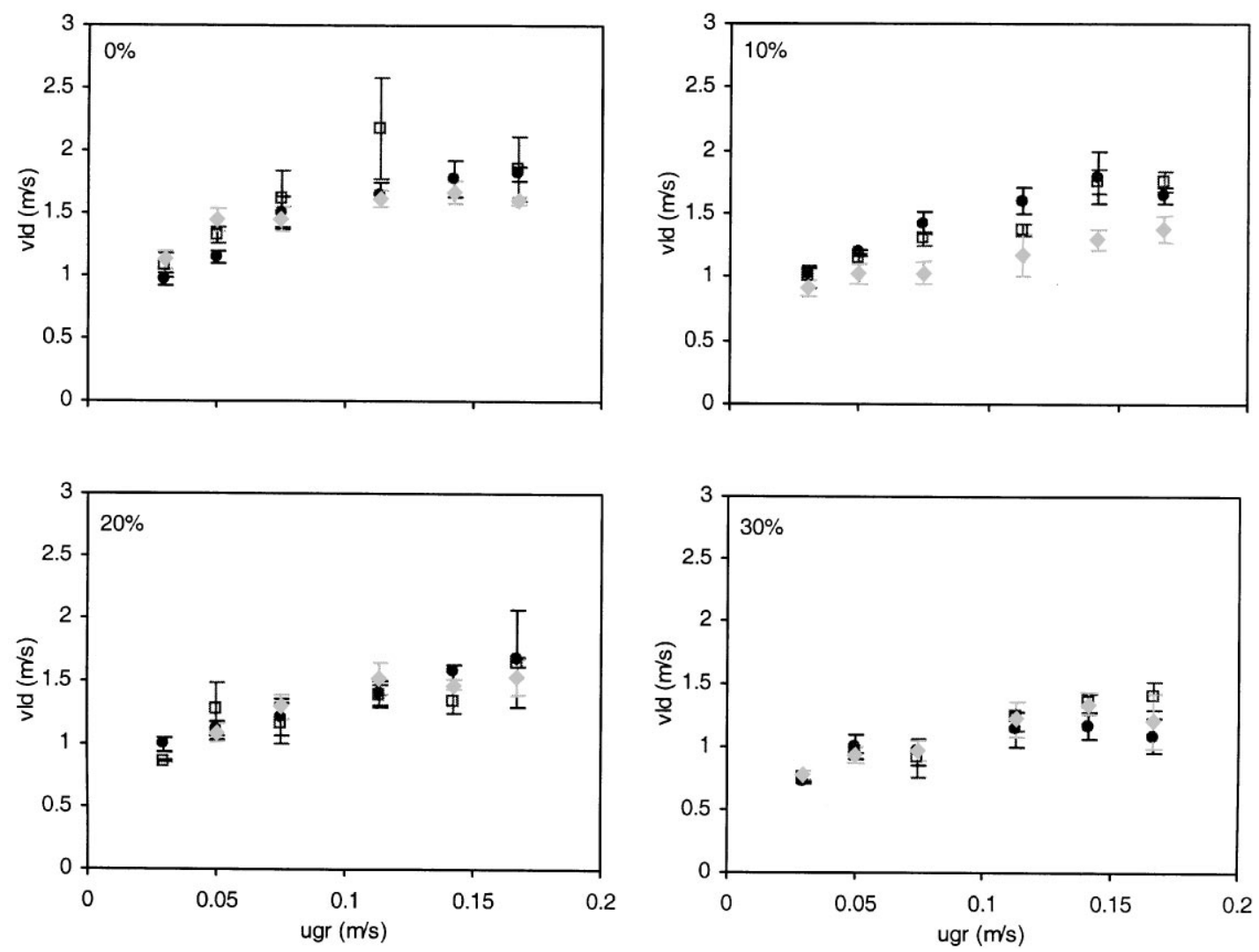

Fig. 7. Influence of riser superficial gas velocity $\left(u_{g r}\right)$ on the downcomer linear liquid velocity $\left(v_{l d}\right)$, for different solids loading $(0,10,20$ and $30 \% \mathrm{v} / \mathrm{v})$ and three distributing plate orifice diameters

- $1.6 \mathrm{~mm} ; \square-1.0 \mathrm{~mm}$;

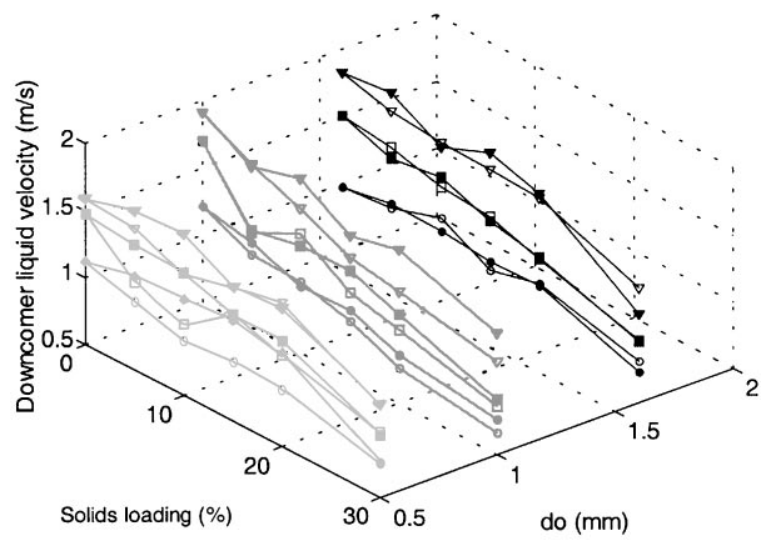

Fig. 8. Influence of solids loading and solids density on downcomer linear liquid velocity, for three distributing plate orifice diameters $\left(d_{o}\right)$ and for different airflow rates $(2100 \mathrm{l} / \mathrm{h}$ : $\circ-\mathrm{LD}, 0-\mathrm{HD} ; 5300 \mathrm{l} / \mathrm{h}$ : $\square$ - LD, $\mathbf{\square}$ - HD; 11800 l/h: $\nabla$ - LD, $\nabla$ - HD): LD - "low-density solids"; HD - "high-density solids".

loading up to $30 \%$ (v/v), according to Eqs. (1) and (2). In general, there is a good agreement between the experimental and the estimated data. The experimental values of riser gas holdup can be predicted, for all the experimental conditions, with an error of $\pm 10 \%$ (Fig. 11), while calculated values of downcomer liquid velocity differ from the experimental ones in a range of $\pm 15 \%$ (Fig. 11). Evidence suggests that the proposed model can predict with high accuracy the riser gas holdup and the liquid velocity in a three-phase external-loop airlift reactor working in a wide range of solids loading, airflow rates and distributing plate orifice diameter, with solids with low densities.

For the estimation of riser gas holdup and downcomer linear liquid velocity, the distributing factor, $C$, the terminal velocity of a single bubble, $U_{b t}$, and the parameter $\beta$ were optimized, with obtained values presented in Table 1 . Observing values of the distributing factor $C$, it can be seen that it decreases with the increase of solids loading. For 1 and $1.6 \mathrm{~mm}$ distributing plate orifice diameters, there is, however, a small increase from 0 to $10 \%$ of "low-density solids", which may be due to the perturbation of flux by the introduction of solids. When, however, more solids are added, the flux becomes more uniform and values of $C$ approaches 1 . Moreover, values of the distributing factor that differ significantly from 1 indicate significant non-uniformity of radial flow profile in the riser, which is, indeed, a predictable result for the heterogeneous bubbling mode and the riser diameter used (Snape et al., 1995). 


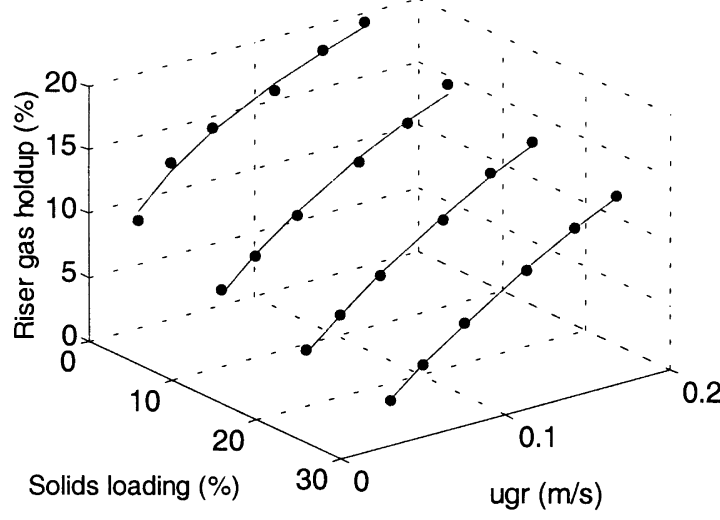

Solids loading (\%)

(aL)

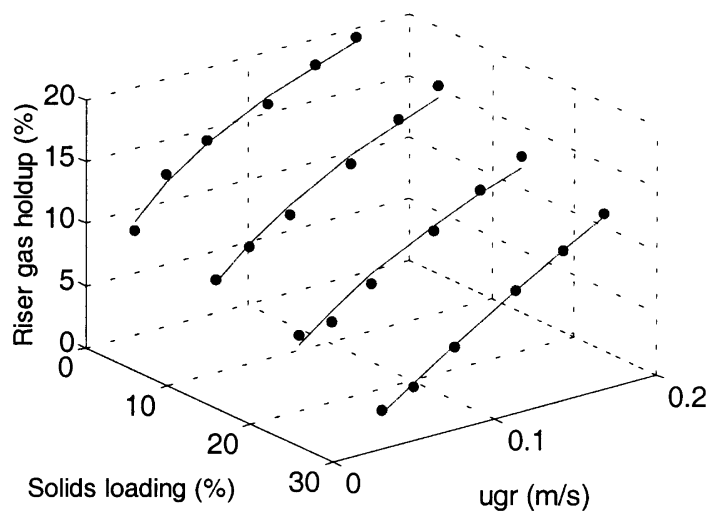

(aH)

(bL)

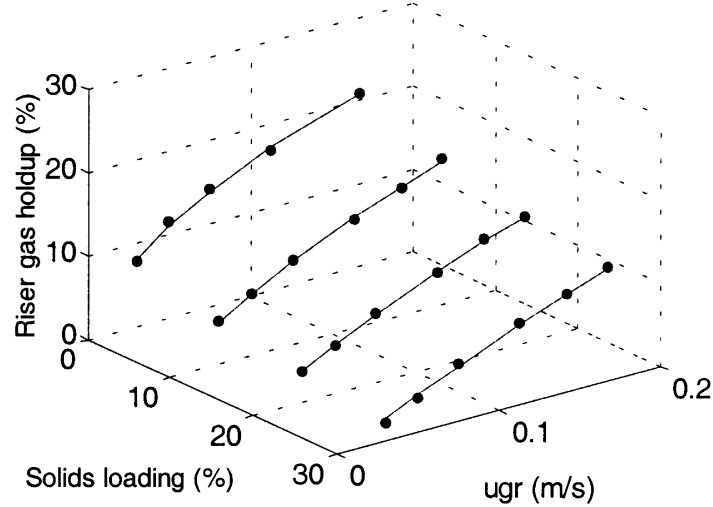

(bH)

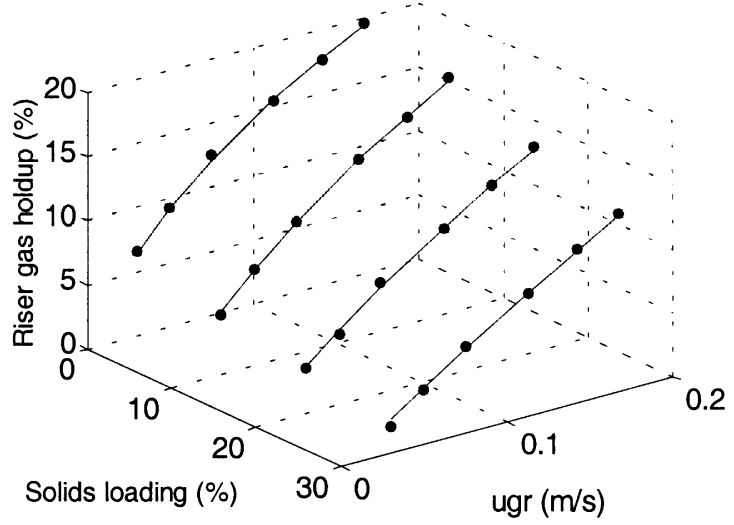

(cH)

Fig. 9. Comparison between the experimental (-) and the calculated values (-) of the riser gas holdup (Eq. (1)), for the three distributing plates - (a) $0.5 \mathrm{~mm}$, (b) $1.0 \mathrm{~mm}$, (c) $1.6 \mathrm{~mm}$ - and for the "low" (L)- and "high" (H)-density solids.

For the distributing plate with $0.5 \mathrm{~mm}$ orifice diameter and the two-phase system, some of the values of distributing factor, $C$, and terminal rise velocity of a single bubble, $U_{b t}$, are out of the range expected for these parameters. This is the consequence of the different behaviour observed for the riser gas holdup in this case (Fig. 2), where a change of bubbling mode seems to occur.
A similar result was obtained by Snape et al. (1995) when tried to apply the Zubber and Findlay "drift flux model" to the results obtained in a two-phase external-loop airlift reactor with a distributing plate with orifices diameter of $0.5 \mathrm{~mm}$. They found that the "drift flux" plot - $U_{g} / \varepsilon_{r}$ vs. $\left(U_{g}+U_{l}\right)$ - was not linear but appeared to be comprised of three linear sections with changes of slope, 


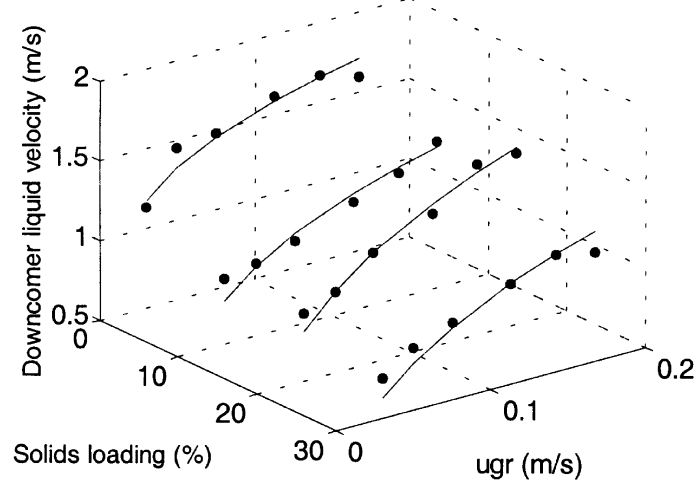

(aL)

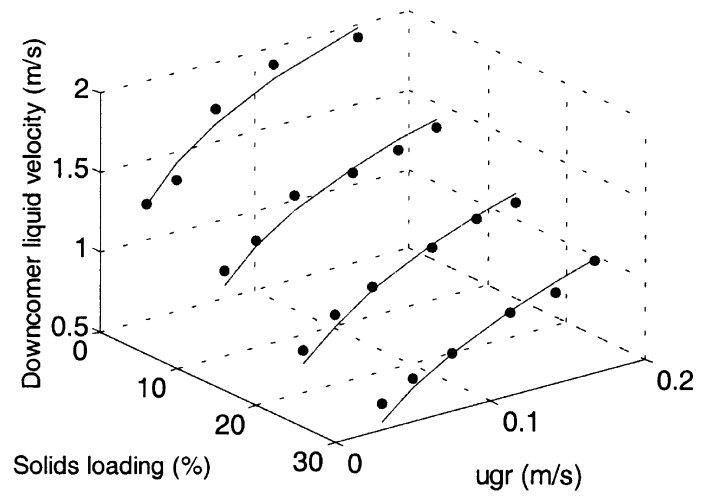

(bL)

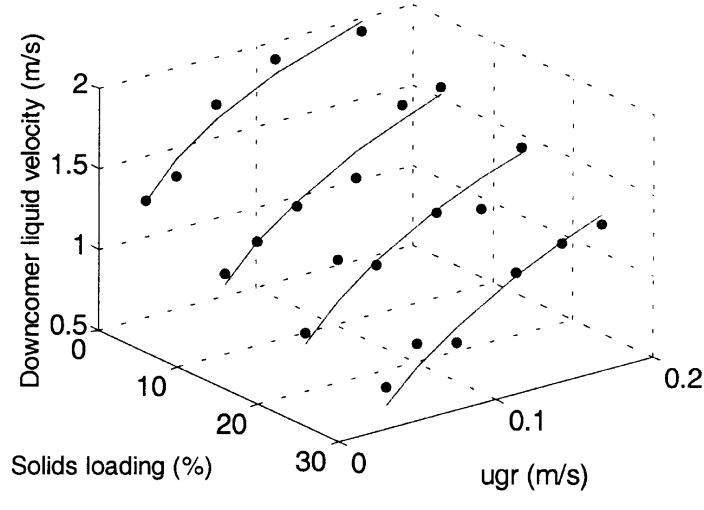

(bH)

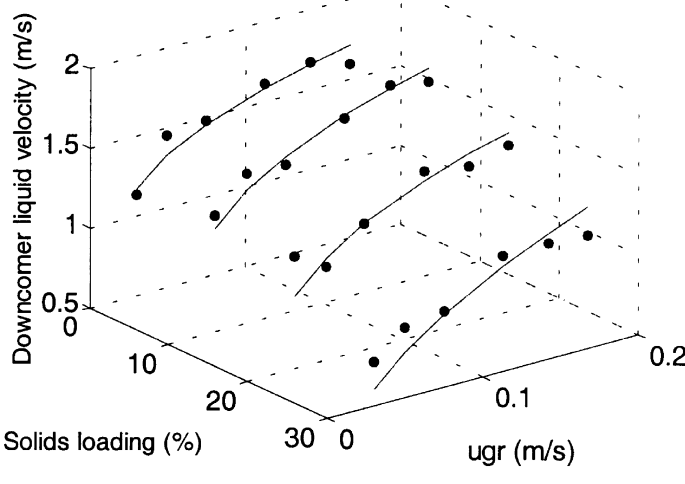

(aH)

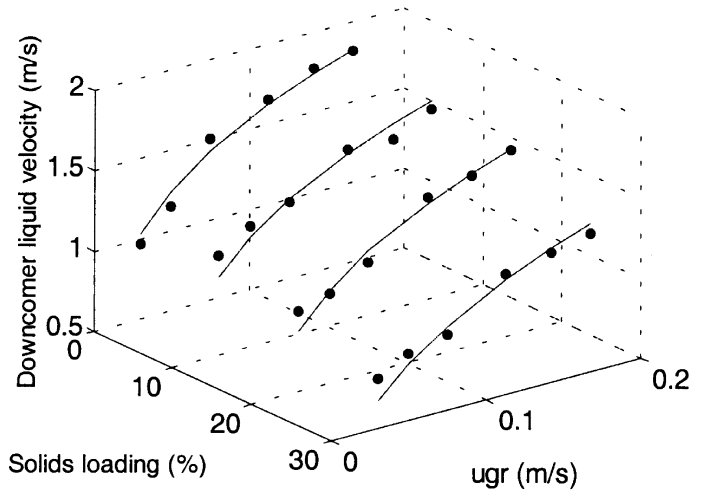

(cL)

Fig. 10. Comparison between the experimental () and the calculated values ( - ) of the downcomer linear liquid velocity (Eq. (2)) for the three distributing plates - (a) $0.5 \mathrm{~mm}$, (b) $1.0 \mathrm{~mm}$, (c) $1.6 \mathrm{~mm}$ - and for the "low" (L)- and "high" (H)-density solids.

which corresponded to the changes of bubbling regime from homogeneous to transition to heterogeneous. For the same reactor but for a plate of $1.6 \mathrm{~mm}$ diameter holes, they found values of $C=1.5$ and $U_{b t}=0.263 \mathrm{~m} / \mathrm{s}$, not very different from those found in this work for $1.6 \mathrm{~mm}$ and $0 \%$ of solids $\left(C=1.82\right.$ and $\left.U_{b t}=0.22 \mathrm{~m} / \mathrm{s}\right)$.

It can also be observed in Table 1 that values of the distributing factor $C$ smaller than 1 were obtained for the three distributing plates when working with $30 \%$ of "high-density solids". In these conditions, the system behaviour deviates considerably from a two-phase system and the model is not so accurate as with "low-density solids" or low solids loading. This is corroborated by the values found for the parameter $\beta$ which, for the distributing plate with orifices diameter of $1.0 \mathrm{~mm}$, exhibits a constant increase with the increase of solids loading while, for the distributing plate of $1.6 \mathrm{~mm}$ orifices diameter, only presents a considerable increase for high solids loading (from 20 to $30 \%$ of solids). Parameter $\beta$ includes a correction factor $\alpha$ (Eq. (3)), which was introduced in the 

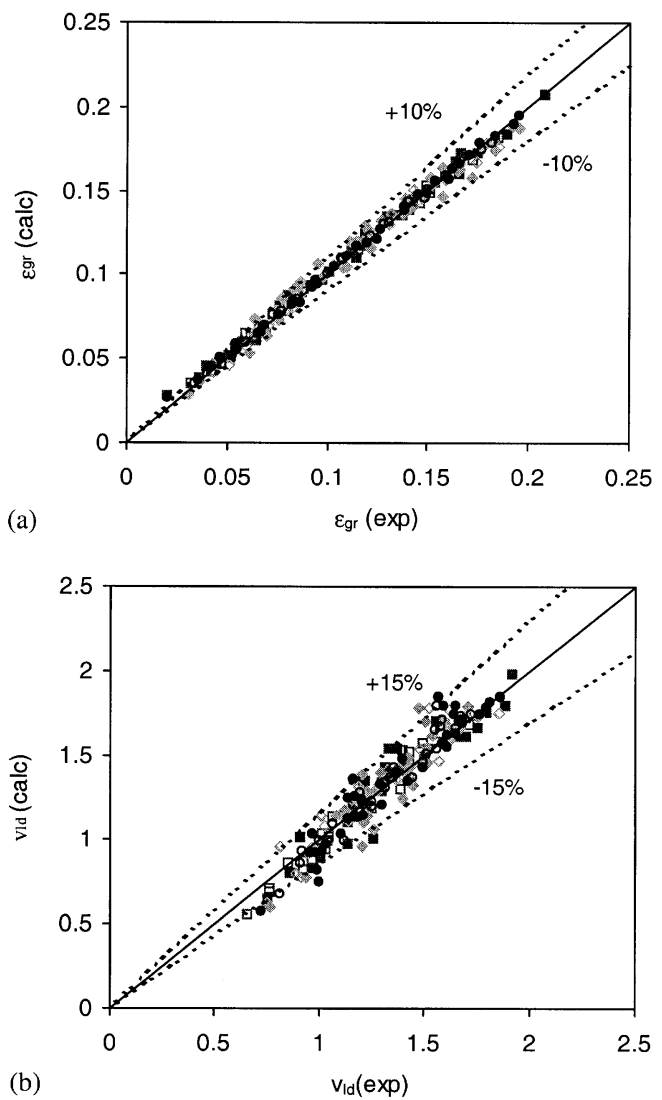

Fig. 11. Predicted values vs. experimental values of riser gas holdup (a) and downcomer linear liquid velocity (b), for all the experimental conditions (1.6 mm: $\circ$ - LD, - HD; $1.0 \mathrm{~mm}: \square-\mathrm{LD}, \mathbf{\square}-\mathrm{HD}$; $0.5 \mathrm{~mm}: \diamond-\mathrm{LD}, \diamond-\mathrm{HD}):$ LD - "low-density solids"; HD - "highdensity solids". calculation of the friction factor so that Blasius equation for one-phase (Perry \& Green, 1984) could be adapted to two and three-phase systems and attend to the higher friction losses present in these cases. The increase of parameter $\beta$ may be the result of the increase of that correction factor, since for high solids loading the flux differs considerably from the flux of one-phase system and the friction losses are much higher.

Confirming what was reported for parameters $C$ (values too high) and $U_{b t}$ (negative values) obtained with the distributing plate of $0.5 \mathrm{~mm}$ orifices diameter, parameter $\beta$ does not have a well-defined trend, probably due to the already mentioned change of bubbling regime. Still, the increase from 20 to $30 \%$ of solids is also observed.

Values of $U_{b t}$ increase with the increase of solids loading in all the experimental conditions studied. Such results can be ascribed to the character of the bubble bed in the riser. In the "drift flux model" (Young, Carbonell \& Ollis, 1991), $U_{b t}$ is the terminal velocity of a single bubble, assuming that bubbles do not interact, that is, each bubble moves independently and is not affected by the presence of other bubbles. However, Verlaan and Tramper (1987) reported that bubbles tended to aggregate in the center of the column as the solids loading increase. Therefore, bubble coalescence was more intense at higher solids loading, with consequent increase in the diameter of the bubbles and the rise in velocity. Thus, bubbles do not move independently but in a swarm of bubbles rising with very high velocities. This is what happens for high solids loading (20 and $30 \%$ ), for which $U_{b t}$ is outside the range of $0.2-0.4 \mathrm{~m} / \mathrm{s}$ presented in literature for two-phase systems (Bando et al., 1990; Lu et al., 1995; Snape et al., 1995).

Table 1

Values of the optimized distributing factor $(C)$, terminal rise velocity of a single bubble $\left(U_{b t}\right)$ and parameter $\beta$ of the model, for three distributing plate orifice diameters, several solids loading and the "high"- and "low-density solids"

\begin{tabular}{|c|c|c|c|c|c|c|c|}
\hline \multirow{2}{*}{$\begin{array}{l}\text { Distributing } \\
\text { plate }(\mathrm{mm})\end{array}$} & \multirow{2}{*}{$\begin{array}{l}\text { Solids } \\
\text { loading (\%) }\end{array}$} & \multicolumn{3}{|c|}{ "Low-density solids" } & \multicolumn{3}{|c|}{ "High-density solids" } \\
\hline & & $C$ & $U_{b t}$ & $\beta$ & $C$ & $U_{b t}$ & $\beta$ \\
\hline & 10 & 2.35 & 0.28 & 0.019 & 2.67 & 0.037 & 0.0048 \\
\hline & 20 & 1.54 & 0.55 & 0.0076 & 2.72 & 0.25 & 0.0055 \\
\hline & 30 & 1.43 & 0.71 & 0.017 & 0.65 & 1.01 & 0.012 \\
\hline & 10 & 2.14 & 0.22 & 0.010 & 1.67 & 0.40 & 0.0056 \\
\hline & 20 & 1.53 & 0.58 & 0.016 & 1.39 & 0.65 & 0.0060 \\
\hline & 30 & 1.20 & 0.77 & 0.024 & 0.64 & 1.04 & 0.0082 \\
\hline \multirow[t]{2}{*}{1.6} & 0 & 1.82 & 0.22 & 0.0069 & 1.82 & 0.22 & 0.0069 \\
\hline & 10 & 2.11 & 0.24 & 0.0066 & 1.39 & 0.44 & 0.0058 \\
\hline
\end{tabular}




\section{Conclusions}

Experiments were conducted to investigate the effect of the distributing plate orifices diameter, the airflow rate, the solids loading and density on the riser gas holdup, the circulation time and the downcomer liquid velocity of a three-phase external-loop airlift reactor. It was found that the distributing plate orifices diameter does not have a significant influence on the parameters studied, being only observed slight changes of riser gas holdup and circulation time, for low airflow rates and low solids loading, and on liquid velocity, for $10 \%$ of solids. This reduced effect of the gas distributor in airlift reactors, when compared with bubble columns, can be ascribed to the influence of superimposed liquid flow on the flow pattern and bubble rise velocity in the riser, enhanced due to the presence of the solid phase. On the contrary, airflow rate and solids loading have a great effect on riser gas holdup, circulation time and downcomer liquid velocity. The increase of airflow rate leads to an increase of riser gas holdup and liquid velocity while the circulation time, consequently, decreases. In opposition, the increasing introduction of solids produces a decrease of the gas holdup and liquid velocity and an increase of circulation time. There is no well-defined trend of the effect of solids density, in the range of values studied, on the studied hydrodynamic characteristics of the three-phase external-loop airlift reactor.

From the results presented, it can be concluded that the model developed by Freitas et al. (1999) predicts the experimental values of riser gas holdup and downcomer linear liquid velocity obtained, for all the experimental cases studied, with high accuracy (with an error of \pm 10 and $\pm 15 \%$, respectively). The distribution factor decreases, in general, with the increase of solids loading while the terminal velocity of a single bubble increases, as a consequence of the increase of coalescence deriving from the increase of the interaction between the bubbles. The parameter $\beta$ does not have a very defined trend, presenting only a significant increase with solids loading for $30 \%$ of solids.

\section{Notation}

A cross-sectional area, $\mathrm{m}^{2}$

C distribution factor

$D$ diameter, $\mathrm{m}$

$g$ gravitational acceleration, $\mathrm{m} / \mathrm{s}^{2}$

$H$ length, $\mathrm{m}$

$k_{f} \quad$ friction loss coefficient

$U \quad$ superficial velocity, $\mathrm{m} / \mathrm{s}$

$U_{b t}$ terminal rise velocity of a single bubble, $\mathrm{m} / \mathrm{s}$

$v \quad$ linear velocity, $\mathrm{m} / \mathrm{s}$

$d_{o} \quad$ distributing plate orifice diameter
Greek letters

$\begin{array}{ll}\alpha & \text { correction factor } \\ \beta & \text { parameter } \\ \varepsilon & \text { holdup } \\ \mu & \text { viscosity, } \mathrm{N} \mathrm{s} \\ \rho & \text { density, } \mathrm{kg} / \mathrm{m}^{3}\end{array}$

\section{Subscripts}

$b$ bottom section

d downcomer

$g$ gas

$h$ homogeneous phase

$l$ liquid

$r$ riser

$s \quad$ solid

$t$ top section

\section{Acknowledgements}

This work was supported by FCT (Fundação para a Ciência e a Tecnologia), under project PRAXIS/2/2.1/ BIO/1061/95 and grant GGP XXI/BD/2937/96 awarded to Carla Maria Duarte de Freitas, by EC, under INCOCOPERNICUS contract $\mathrm{N}^{\circ}$ ERB IC15-CT98-0904 and by Instituto de Biotecnologia e Química Fina (IBQF).

\section{References}

Bando, Y., Nishimura, M., Sota, H., Hattori, M., Sakai, N., \& Kuraishi, M. (1990). Flow characteristics of three-phase fluidized bed with draft tube - effect of outer column diameter and determination of gas-liquid interfacial area. Journal of Chemical Engineering Japan, 23, 587-592.

Bentifraouine, C., Xuereb, C., \& Riba, J. -P. (1997). An experimental study of the hydrodynamic characteristics of external loop airlift contactors. Journal of Chemical Technology and Biotechnology, 69, 345-349.

Chisti, M. Y. (1989), Airlift reactors (pp. 63) London: Elsevier.

Chisti, M. Y., Halard, B., \& Moo-Young, M. (1988). Liquid circulation in airlift reactors. Chemical Engineering Science, 43, 451-457.

Freitas, C., \& Teixeira, J. T. (1997). Hydrodynamic studies in an airlift reactor with an enlarged degassing zone. Bioprocessing Engineering, 18, 267-279.

Freitas, C., Fialová, M., Zahradnik, J., \& Teixeira, J. T. (1999). Hydrodynamic model for three-phase internal and external-loop airlift reactors. Chemical Engineering Science, 54, 5253-5258.

Garcia-Calvo, E., \& Letón, P. (1996). Prediction of gas hold-up and liquid velocity in airlift reactors using two-phase flow friction coefficients. Journal of Chemical Technology and Biotechnology, 67, 388-396.

Gavrilescu, M., \& Tudose, R. Z. (1998). Modelling of liquid circulation velocity in concentric-tube airlift reactors. Chemical Engineering Journal, 69, 85-91.

Hwang, S.-J., \& Cheng, Y.-L. (1997). Gas holdup and liquid velocity in three-phase internal-loop airlift reactors. Chemical Engineering Science, 52, 3949-3960. 
Kastánek, F., Zahradnik, J., Kratochvil, J., \& Cermák, J. (1993). Chemical reactors for gas-liquid systems. New York: Ellis Horwood.

Kemblowski, Z., Przywarski, J., \& Diab, A. (1993). An average gas hold-up and liquid circulation velocity in airlift reactors with external loop. Chemical Engineering Science, 48, 4023-4035.

Kochbeck, B., Lindert, M., \& Hempel, D. C. (1992). Hydrodynamics and local parameters in three-phase-flow in airlift-loop reactors of different scale. Chemical Engineering Science, 47, 3443-3450.

Lu, W.-J., Hwang, S.-J., \& Chang, C. -M. (1995). Liquid velocity and gas holdup in three-phase internal-loop airlift reactors with low-density particles. Chemical Engineering Science, 40, 1301-1310.

Merchuk, J. C. (1986). Gas hold-up and liquid velocity in a two dimensional air lift reactor. Chemical Engineering Science, 41, 11-16.

Onken, U., \& Weiland, P. (1983). Airlift fermenters: Construction, behaviour, and uses advances in biotechnological processes, Vol. 1. (pp. 67-95). New York: Alan R. Liss.

Perry, R. H., \& Green, D. W. (1984). Perry's chemical engineers' handbook (6th ed.). (p. 564). New York, USA: McGraw Hill.

Snape, J. B., Fialová, M., Zahradnik, J., \& Thomas, N. H. (1992). Hydrodynamic studies in an external loop airlift reactor containing aqueous electrolyte and sugar solutions. Chemical Engineering Science, 47, 3387-3394.
Snape, J. B., Zahradnik, J., Fialová, M., \& Thomas, N. H. (1995). Liquid-phase properties and sparger design effects in an external-loop airlift reactor. Chemical Engineering Science, 50, 3175-3186.

Verlaan, P., \& Tramper, J. (1987). Hydrodynamics, axial dispersion and gas-liquid oxygen transfer in an airlift-loop bioreactor with threephase flow. International conference on bioreactors and biotransformations, paper I4 (pp. 363-373).

Vicente, A., \& Teixiera, J. T. (1995). Hydrodynamic performance of a three-phase airlfit bioreactor with an enlarged degassing zone. Bioprocessing Engineering, 14, 17-22.

Weiland, P. (1984). Influence of draft tube diameter on operation behaviour of airlift loop reactors. German Chemical Engineering, 7, 374-385.

Young, M. A., Carbonell, R. G., \& Ollis, D. F. (1991). Airlift bioreactors: Analysis of local two-phase hydrodynamics. AIChE Journal, 37, 403-428.

Zahradnik, J., Fialová, M., Kastanek, F., Green, K. D., \& Thomas, N. H. (1995). The effect of electrolytes on bubble coalescence and gas holdup in bubble column reactor. Chemical Engineering Research and Design, 73, 341-346. 